\title{
Visual Stimulus-Dependent Changes in Interhemispheric EEG Coherence in Humans
}

\author{
M. G. KNYAZEVA, ${ }^{1,2}$ D. C. KIPER, ${ }^{2}$ V. Y. VILDAVSKI, ${ }^{3}$ P. A. DESPLAND,${ }^{4}$ M. MAEDER-INGVAR, ${ }^{4}$ AND \\ G. M. INNOCENTI ${ }^{2,5}$ \\ ${ }^{1}$ Research Institute of Developmental Physiology, 119121 Pogodinskaya 8-2, Moscow, Russia; ${ }^{2}$ Institut de Biologie \\ Cellulaire et de Morphologie, Université de Lausanne, 1005 Lausanne, Switzerland; ${ }^{3}$ Smith-Kettlewell Eye Research \\ Institute, San Francisco, California 94115; ${ }^{4}$ Department of Neurology, Centre Hospitalier Universitaire Vaudois, 1011 \\ Lausanne, Switzerland; and ${ }^{5}$ Division of Neuroanatomy and Brain Development, Department of Neuroscience, Karolinska \\ Institutet, S-17177 Stockholm, Sweden
}

\begin{abstract}
Knyazeva, M. G., D. C. Kiper, V. Y. Vildavski, P. A. Despland, M. Maeder-Ingvar, and G. M. Innocenti. Visual stimulus-dependent changes in interhemispheric EEG coherence in humans. J. Neurophysiol. 82: 3095-3107, 1999. We analyzed the coherence of electroencephalographic (EEG) signals recorded symmetrically from the two hemispheres, while subjects $(n=9)$ were viewing visual stimuli. Considering the many common features of the callosal connectivity in mammals, we expected that, as in our animal studies, interhemispheric coherence (ICoh) would increase only with bilateral iso-oriented gratings located close to the vertical meridian of the visual field, or extending across it. Indeed, a single grating that extended across the vertical meridian significantly increased the EEG ICoh in normal adult subjects. These ICoh responses were obtained from occipital and parietal derivations and were restricted to the gamma frequency band. They were detectable with different EEG references and were robust across and within subjects. Other unilateral and bilateral stimuli, including identical gratings that were effective in anesthetized animals, did not affect ICoh in humans. This fact suggests the existence of regulatory influences, possibly of a top-down kind, on the pattern of callosal activation in conscious human subjects. In addition to establishing the validity of EEG coherence analysis for assaying cortico-cortical connectivity, this study extends to the human brain the finding that visual stimuli cause interhemispheric synchronization, particularly in frequencies of the gamma band. It also indicates that the synchronization is carried out by cortico-cortical connection and suggests similarities in the organization of visual callosal connections in animals and in man.
\end{abstract}

\section{N T R O D U C T I O N}

Over the last few years, animal studies of brain rhythms in the gamma band $(>20 \mathrm{~Hz})$ revealed two correlates of alert states during sensory stimulation or active behavior: local synchronization of activity, reflected in a power increase, and/or distant synchronization between remote cortical areas, shown by cross-correlation or coherence analyses (Bressler et al. 1993; Eckhorn 1994; Engel et al. 1991; Kreiter and Singer 1992). The importance of these findings is twofold. First, the synchronization of cortical activity might represent the neural substrate for Gestalt-type perceptual operations (reviewed in Singer and Gray 1995; von der Malsburg 1995). Second, to the

The costs of publication of this article were defrayed in part by the payment of page charges. The article must therefore be hereby marked "advertisement" in accordance with 18 U.S.C. Section 1734 solely to indicate this fact. extent that the distant synchronization of fast cortical activity depends on cortico-cortical connections (Engel et al. 1991; Munk et al. 1995; for other references see Kiper et al. 1999), its analysis might provide a way of assessing the functional connectivity between cortical areas. This would be particularly desirable in human studies, for which reliable methods for analyzing cortico-cortical connections are scarce.

In animal studies, activity changes in the gamma frequency band were detected by intracortical recordings, an invasive technique mostly unusable in humans. On the other hand, the mere possibility of recording gamma activity from the human scalp recently was a debated topic (Lutzenberger et al. 1997; Menon et al. 1996). Thus it is important to determine whether stimulus- and connectivity-dependent changes of fast brain rhythms can be reliably identified by electroencephalographic (EEG) techniques in humans. This study was designed to replicate in humans the essential features of the animal experiments reported by Kiper et al. (1999). In that paper, we showed that in ferrets, stimulus-induced distant synchronization of cortical activity similar to that reported in cats and monkeys could be detected using epidural EEG recording and analysis of the interhemispheric coherence. An increased coherence in the gamma band was obtained for visual stimuli that activate callosally connected neuronal pools in the two hemispheres, suggesting that coherence changes can indeed be used to assay cortico-cortical connectivity.

A few noninvasive EEG and magnetoencephalography (MEG) studies in humans described gamma band responses to stimuli of different modalities (Desmedt and Tomberg 1994; Joliot et al. 1994; Kristeva-Feige et al. 1993; Lutzenberger et al. 1995; Makeig 1993; Müller et al. 1996; Pantev et al. 1991; Pullvermüller et al. 1995; Sannita 1994; Sannita et al. 1995; Tallon et al. 1995; Tallon-Baudry et al. 1997; Tiitinen et al. 1993). In the visual domain, Müller et al. (1996) observed a gamma power increase in occipital and parietal regions in humans viewing a single moving bar but not two bars moving in opposite directions. Similarly, Lutzenberger et al. (1995) found that gamma band power increased in the occipital region in response to coherently moving bars. Recently, TallonBaudry et al. (1997) reported a wide-spread transient power increase in the gamma band when human subjects were able to detect a figure hidden in a background. The results of these experiments are considered to support the hypothesis that the 
binding of perceptual features is achieved by synchronization of activity in the gamma band. However, it remains unclear which specific neural circuits are responsible for the synchronization.

In conclusion, it remains to be proven that cortico-cortical connections participate in synchronizing cortical activity in humans, as it appears to be the case in animals. This motivated the present study of stimulus induced power and coherence changes of EEG signals. The rationale for analyzing specifically the interhemispheric coherence dynamics induced by visual stimuli is identical to that discussed in relation to the animal work (Kiper et al. 1999), under the assumption that the relevant features of callosal connections between the visual areas are preserved across species, including man.

\section{METHODS}

\section{Subjects and experimental procedures}

Nine adult volunteers (5 women, 4 men), 19-37 years of age and without neurological history, participated in this study. All subjects but one were right-handed and had normal or corrected to normal vision. The EEGs were recorded in the resting state (both with closed and open eyes) and during visual stimulation. The ongoing EEG tracings were constantly monitored during the experiment to keep the subject's wakefulness level and the quality of recording under steady watch. To check the within-subject reliability of our data, the EEGs of two subjects were recorded twice at the 4- to 5-mo interval. All the procedures conformed to the Declaration of Helsinki (1964) by the World Medical Association concerning human experimentation.

\section{Visual stimulation}

The stimuli were presented on a Eizo T-560 i monitor, driven by an AT Truevision Vista graphics board, with a refresh rate of $104 \mathrm{~Hz}$, interlaced. A small white square in the center of the screen served as fixation point and was alternated with stimulus frames. The subjects were instructed to maintain their gaze on the fixation point. Adequate fixation was monitored by on-line video recordings. The stimuli were vertical rectangular patches of black-and-white sinusoidal gratings, with a space-averaged luminance of $32 \mathrm{~cd} / \mathrm{m}^{2}$, presented on a uniform background of equal luminance. At the viewing distance we used (42 $\mathrm{cm}$ ), the screen subtended 39 by $28^{\circ}$ of visual angle, and the patches 13 by $24^{\circ}$. All the sinusoidal gratings had a spatial frequency of 0.5 c/deg, a contrast of $50 \%$, and drifted with a temporal frequency of 2 Hz. The stimuli described below were presented in individual sequences repeated for a minimum of 50 times and randomized across subjects. Each stimulus was presented for $2 \mathrm{~s}$ (a duration shown to be appropriate by our animal experiments, Kiper et al. 1999). The interstimulus interval was variable, and averaged $\sim 1.5 \mathrm{~s}$. Longer intervals (breaks) were introduced when the subjects showed signs of fatigue or discomfort.

1) Left hemifield stimulus. A single patch of horizontally oriented, downward drifting gratings was presented to the left of the fixation point. The center of the patch was located $7^{\circ}$ from the fixation point.

2) Right hemifield stimulus. Identical to 1 ), but presented to the right of the fixation point.

3) Bilateral identical stimuli. Gratings 1) and 2) were simultaneously presented. Therefore a vertical strip of visual field of $0.5^{\circ}$ on each side of the vertical meridian (VM) was not stimulated.

4) Bilateral different stimuli. The grating to the left of the fixation point was as described above, but that on the right was vertically oriented and drifted to the right.

In addition to these four "close" conditions, we ran the same stimulations with gratings located further away from the fixation point. In that case, the patch centers were located $13^{\circ}$ to the side of the fixation point. Therefore the gratings did not stimulate a vertical strip of $6.5^{\circ}$ on each side of the VM. We refer to these as the "far" conditions.

5) Whole screen identical stimulus. This consisted of a single patch of downward drifting horizontal grating $\left(27\right.$ by $24^{\circ}$ ) centered on the fixation point.

6) Whole screen different stimuli. In this case, we presented a patch equal in extent to the whole screen identical stimulus consisting of a horizontal downward drifting grating on the left, and of a vertical rightward drifting grating on the right.

7) Background. As a reference condition, we used a uniform gray screen with same space-averaged luminance as the other stimuli.

The stimulation protocol for humans was, thus similar to that of our animal experiments (Kiper et al. 1999).

\section{EEG recording and processing}

The EEGs were recorded according to the 10-20 system (Jasper 1958; Nuwer et al. 1994) from Fp1, Fp2, F3, F4, C3, C4, P3, P4, O1, O2, T3, T4, T5, and T6 referenced to Fpz using a Neurofax encephalograph (Deltamed, France). Electrode sites determined by conventional measurements were treated with abrasive paste, and $\mathrm{Ag}-\mathrm{AgCl}$ cup electrodes were affixed with collodion and filled with conductive electrode paste. This procedure allowed us to keep all electrode impedance below $5 \mathrm{k} \Omega$ for extended periods of time. The signals were filtered by an analogue band-pass filter (time constant of $1 \mathrm{~s}$, upper cutoff at $100 \mathrm{~Hz}$ ), a $50-\mathrm{Hz}$ notch filter, and sampled at a frequency of $256 \mathrm{~Hz}$ to avoid contamination of the band under study $(\leq 46 \mathrm{~Hz})$ from undersampled higher frequency components. We used the PCbased "EEG Lab" software package (Metrica, Moscow, Russia) for spectral processing.

Several methodological issues should be taken into account while analyzing gamma activity by means of noninvasive EEG techniques (Jürgens et al. 1995; Lutzenberger et al. 1997; Pulvermüller et al. 1997). Because coherence data depend on the derivation type (Andrew and Pfurtscheller 1996) and, in particular, are highly sensitive to signal variations at the common reference (Fein et al. 1988), we checked the reproducibility of our results under different montage schemes. Because there exists no universally accepted reference electrode, we digitally converted our initial Fpz reference into common average, bipolar, and ipsilateral earlobe reference montages, which all emphasize different properties of the EEG signals. In general, the common average reference acts like a spatial high-pass filter removing the DC component from the recorded signal (Lehmann 1986). However, if relatively few electrodes are used, the signal recorded from each active electrode can have a significant impact on the reference level, and this can lead to the emergence of spurious coherence changes over brain areas that are not really reactive (Gibbs and Gibbs 1984; Reilly 1993). Bipolar derivation potentially gives information on local voltage gradients but is highly dependent on the choice of electrode pairs and on the spacing between the electrodes. Electrode pairs located above co-active brain areas can thus fail to detect significant voltage differences (Osselton 1966, 1969). Under our experimental conditions, ipsilateral earlobe reference electrodes represent a good approximation of an ideal remote reference point, not contaminated by visual cortex activity, which is the focus of our study. In this case, any observed visual stimulus-dependent changes in interhemispheric coherence cannot be ascribed to the influence of a common reference, each hemisphere having its own independent reference electrode.

To obtain statistically reliable spectral parameters, 36-70 artifactfree EEG epochs, each of 2-s duration, were selected and processed in each experimental condition for every subject. Subsequently, to test the stability of the changes, the first and the second halves of the 2-s epochs were extracted and processed separately.

The EEG segments containing artifacts, including those due to eye 
movements and excessive muscle activity, were identified on visual inspection and eliminated from further analysis.

To avoid a potential contamination of the data with muscle artifacts, the individually averaged spectral functions were carefully inspected within the frequency range 1-100 Hz. All subjects' responsive EEG frequencies were lower than $50 \mathrm{~Hz}$, below the range of frequencies that is typical of muscle activity (Cacioppo et al. 1990). Thus a significant impact of muscle activity was highly improbable.

Spectral power density (SPD) for every channel and coherence functions for symmetrical interhemisperic pairs of leads (ICoh) were calculated by averaging the primary spectral estimates (computed by fast Fourier transformation) over all epochs and smoothing the averages by Parsen's window. Coherence function (Coh) between two signals $x$ and $y$ at each frequency $f$ was then calculated as

$$
\operatorname{Coh}_{x y}(f)=\left|S_{x y}(f)\right|^{2} /\left[S_{x x}(f) * S_{y y}(f)\right]
$$

where $S_{x y}(f), S_{x x}(f)$, and $S_{y y}(f)$ are cross-spectrum and autospectrum estimates of the $x$ and $y$ signals, respectively. Resulting spectral estimates had effective frequency resolution of $2 \mathrm{~Hz}$ for the data obtained from 2- and 1-s epochs.

\section{Statistical analysis}

Preliminary visual inspection suggested that stimulus-specific responses were elicited within the beta-gamma band, i.e., at frequencies between the alpha range and $50 \mathrm{~Hz}$. However, in some subjects, the beta1-frequencies $(14-25 \mathrm{~Hz})$ appeared to be contaminated by harmonics of the alpha rhythm and, therefore could not be used in all subjects. Thus the resulting gamma band was determined as 25-46 $\mathrm{Hz}$. Because alpha band also seemed to be responsive, it was quantified for the standard range of $8-12 \mathrm{~Hz}$, which well fitted all our subjects. For group data analysis, the individual ICoh and SPD responses for the bands defined above were computed as the differences between the band averages in stimulus and background conditions. Then, the ICoh responses were analyzed as a dependent variable with ANOVA (SPSS, version 7.5). Although their distribution was not normal, we performed ANOVA, because it is robust against deviations from normality, provided that there is the same number of cases in all the groups under comparison, and that their dispersions are not grossly inhomogeneous (Kelly et al. 1997; Morrison 1990). These conditions being satisfied, we assessed the effects of stimulation (factor Stimulus), electrode pair location (factor Location), and EEG frequency band (factor Band) on ICoh responses in the group of nine subjects. The Stimulus factor included three levels (stimuli): wholescreen, identical-close, and different-close. The Location factor had levels corresponding to interhemispheric pairs O1/O2, P3/P4, T5/T6, T3/T4, C3/C4, F3/F4, and Fp1/Fp2 with ipsilateral earlobe or common average references; or to bipolar pairs O1-P3/O2-P4, O1-T5/O2T6, P3-C3/P4-C4, P3-T5/P4-T6, C3-F3/C4-F4, F3-Fp1/F4-Fp2. The Band factor had two levels: the alpha $(8-12 \mathrm{~Hz})$ and the gamma $(25-46 \mathrm{~Hz})$ ranges. Analyses of variance for different EEG montages (with ipsilateral earlobe reference, common average, and bipolar) were performed separately. For the analysis of SPD, where application of ANOVA was questionable because of significant inhomogeneity of the data, we used the Friedman test for several related samples, which does not assume a normal distribution of the data. Multiple comparisons were performed using the conservative Tamhane's $\mathrm{T} 2$ test for samples with unequal variances.

Having in mind to use EEG coherence analysis in future studies of individual cases, we gave special consideration to the reproducibility of the data both within and between subjects. To this end, we applied the nonparametric Wilcoxon's test to mean band values of the SPD and ICoh for single epochs of $2 \mathrm{~s}$ using built-in routines of the "EEG Lab."

\section{RE S U L T S}

\section{Group data analysis of ICoh changes under visual stimulation}

A three-way ANOVA with the following fixed factors: Band (alpha vs. gamma), Stimulus (whole-screen, identical-close, different-close) and Location (symmetrical electrode pairs; see METHODS) was performed on the individual ICoh responses, separately for each of the three montage schemes. For ipsilateral earlobe referenced data, the Band and Stimulus factors were highly significant $\left(F_{1,349}=131.21, P<0.0005\right.$ for Band and $F_{2,349}=11.74, P<0.0005$ for Stimulus $)$. Their interaction $\left(F_{2,349}=11.48, P<0.0005\right)$ indicates that the ICoh responses to the various stimuli were clearly different in the two frequency bands under consideration. Location failed to reach statistical significance $\left(F_{6,349}=1.99, P=0.066\right)$ but significantly interacted with Band $\left(F_{6,349}=6.84, P<0.0005\right)$. This suggests that the topographical variations of the ICoh responses were band-specific. Figure $1, A-C$, illustrates these results.

Indeed, responses in the alpha band consisted in a decreased ICoh in all the derivation pairs and stimulus conditions (Fig. $1 A)$ in contrast to the gamma band location- and stimulusspecific coherence increases (Fig. 1B). Thus the next step was to analyze variance in the gamma band alone.

A two-way ANOVA with Stimulus and Location as factors and ICoh response as a dependent variable confirmed the main effects of both factors at a significance level of $P<0.0005$ $\left(F_{2,174}=23.14\right.$ for Stimulus and $F_{6,174}=6.20$ for Location $)$. The interaction between them was also significant $\left(F_{12,174}=\right.$ 1.99, $P=0.029)$.

Multiple comparisons showed that the ICoh response to the whole screen stimulation was higher than to any of the other two stimuli (identical-close or different-close; $P<0.05$ ) in occipital, parietal, posterior temporal, and central pairs. The ICoh responses associated with the whole screen stimulation depended on the location of the electrode pair. Parietal and occipital responses were similar $(P=0.927)$ : both were larger than the frontal (Fp1/Fp2 and F3/F4) and anterior temporal (T3/T4) pairs $(P<=0.001)$, and marginally larger than central (C3/C4) and posterior temporal (T5/T6) responses $(P \leq$ $0.1)$. No other stimulation condition resulted in such a locationspecific pattern of responses.

Similar results were obtained with common average reference (Fig. 1C), except for a significant ICoh increase during the whole screen condition in the Fp1/Fp2 pair. However, the latter was not confirmed with bipolar derivations (see following text), suggesting that this frontal response is an artifact inherent to the common average montage, and due to activity in the occipital and parietal regions.

The same two-way ANOVA applied to bipolar EEG coherence data showed that the Stimulus and Location factors were significant $\left(F_{2,149}=24.80, P<=0.0005\right.$, and $F_{5,149}=2.32$, $P<0.05$, respectively). Multiple comparisons revealed that ICoh responses in posterior pairs of electrodes only changed as a function of stimulation condition. In summary, for posterior electrode locations all the montage schemes gave consistent results. Therefore we will restrict further descriptions to the ICoh responses computed with ipsilateral earlobe referenced EEG signals. 
A

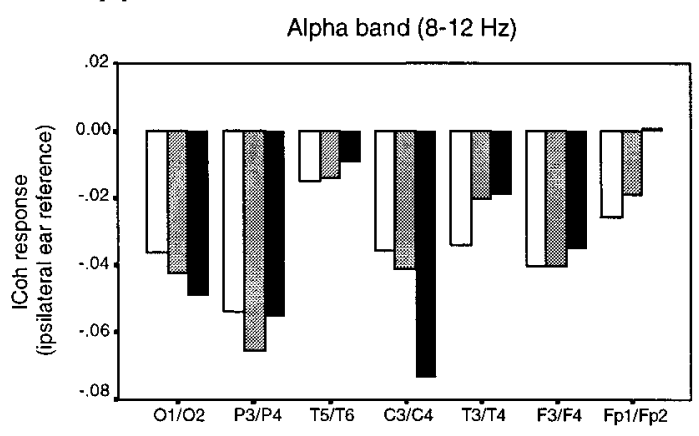

C

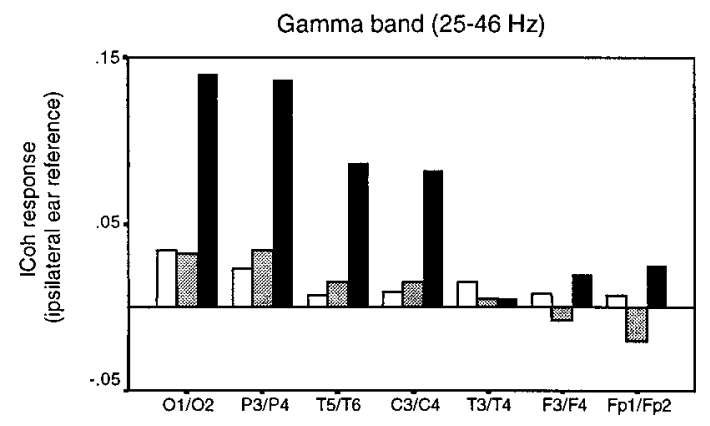

B

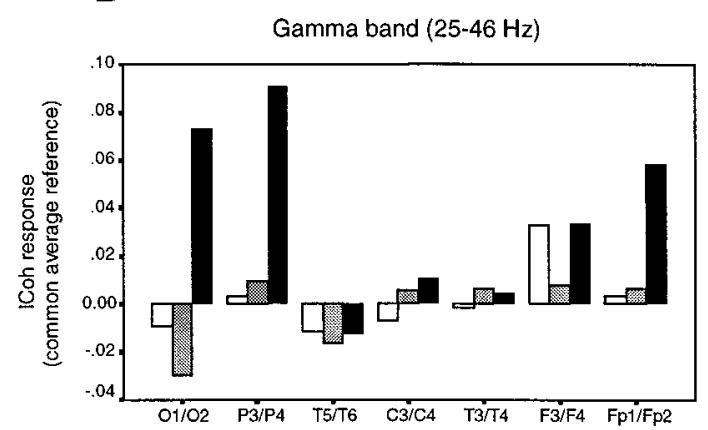

D

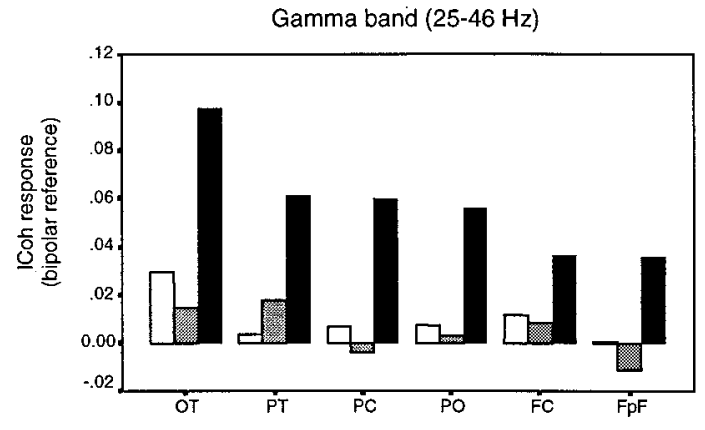

Whole screen identical $\square$ Identical close $\square \quad \square$ Different close

FIG. 1. Group averaged electroencephalogram (EEG) interhemispheric coherence (ICoh) responses in the alpha $(A)$ and gamma $(B-D)$ bands with ipsilateral ear $(A$ and $B)$, common average $(C)$, and bipolar $(D)$ references. In all graphs, the ICoh responses computed as the differences between the mean band values in stimulus (whole screen identical, different close, and identical close) and background conditions are shown. ANOVA showed stimulus- and location-specific ICoh changes for the gamma band only. For $\mathrm{O} 1 / \mathrm{O} 2$ and $\mathrm{P} 3 / \mathrm{P} 4$, the changes were independent of the montage scheme (see text).

\section{Individual ICoh changes under visual stimulation}

The above group statistics are confined to the whole-screen, different-close, and identical-close stimulus conditions, which were presented to nearly all subjects. Systematic ICoh changes were revealed in the gamma band in the occipital and parietal regions. Analysis of the individual data (Table 1) indicated that the gamma band ICoh increase in response to the whole screen stimulation is highly reproducible between subjects.

Indeed, compared with the background condition, it was significant in all but one of the subjects and restricted to the occipital and parietal electrode pairs (Fig. 2).

Individually, some moderate increase was occasionally obtained for the identical-close ( 3 subjects) and different-close (4 subjects) stimulus conditions. A between-conditions comparison showed that ICoh levels were always greater for the whole screen gratings compared with the other stimuli (Table 2), including the whole-screen-different stimulus, which was presented in three experiments.

In five subjects, we used unilateral stimuli close to the VM, as well as a set of far stimuli. These were analyzed by means of individual statistics only. No reproducible ICoh responses were found either for the unilateral-close stimuli (Tables 1 and 2 ), or for any of the far stimuli. Individual examples of spectral curves obtained during the unilateral and the far stimulation are shown in Figs. 3 and 4, respectively.

To determine whether the ICoh changes were reproducible over long time intervals in the same individual, we recorded the EEGs of two subjects (IC and NB) twice, at a several month interval. In both cases, significantly larger responses were obtained with the whole-screen than with other stimuli (Tables 1 and 2).

\section{Temporal stability of the gamma band coherence response}

The data presented so far are based on the analysis of 2-s EEG segments. To study the temporal stability of the ICoh responses during stimulation, we performed a MANOVA with Epoch of analysis as a factor (1st vs. 2nd second), and ICoh values for the $\mathrm{O} 1 / \mathrm{O} 2$ and $\mathrm{P} 3 / \mathrm{P} 4$ pairs as dependent variables, for the background and whole screen conditions separately. This analysis showed no significant changes between the first and second halves of exposure to the stimuli $\left(F_{1,17}=0.580\right.$, $P=0.682$ for background, and $F_{1,17}=0.085, P=0.986$ for the whole screen). In addition, individual statistics also revealed no significant ICoh differences between the first and last seconds in any of the stimulus conditions. The group results and a representative individual example are shown in Fig. 5.

\section{EEG spectral power response to visual stimulation and its relation to the ICoh response in the gamma band}

To reveal possible relations between local and distant synchronization, we analyzed stimulus-induced SPD changes of 
TABLE 1. Individual ICoh values in the gamma band during visual stimulation with close and whole screen gratings, compared to background

\begin{tabular}{|c|c|c|c|c|c|c|c|c|c|c|c|}
\hline Stimuli & $I C$, Experiment 1 & $I C$, Experiment 2 & $N G$ & $D K$ & $L M$ & $L T$ & $N B$, Experiment 1 & $N B$, Experiment 2 & $K L$ & $M G$ & $T R$ \\
\hline & \multicolumn{11}{|c|}{$O 1 / O 2$} \\
\hline Whole screen & $0.575^{\mathrm{a}}$ & $0.433^{b}$ & $0.595^{\mathrm{a}}$ & $0.381^{\mathrm{c}}$ & $0.381^{\mathrm{d}}$ & 0.581 & $0.765^{\mathrm{a}}$ & $0.587^{\mathrm{a}}$ & $0.701^{\mathrm{a}}$ & $0.599^{\mathrm{a}}$ & $0.423^{\mathrm{a}}$ \\
\hline Bilateral identical & 0.432 & $0.381 / 0.376$ & 0.457 & 0.315 & 0.294 & 0.559 & $0.678^{a}$ & $0.568^{a}$ & 0.415 & No data & 0.338 \\
\hline Bilateral different & $0.486^{\mathrm{d}}$ & 0.382 & 0.455 & $0.352^{b}$ & 0.313 & 0.545 & $0.605^{\mathrm{a}}$ & $0.481^{\mathrm{e}} / 0.501^{\mathrm{e}}$ & $0.438^{\mathrm{e}} / 0.479^{\mathrm{b}}$ & 0.523 & No data \\
\hline Left & $0.458^{\mathrm{e}}$ & No data & 0.476 & 0.321 & 0.289 & 0.540 & No data & No data & No data & No data & No data \\
\hline Right & $0.458^{\mathrm{e}}$ & No data & 0.429 & 0.329 & 0.293 & 0.550 & No data & No data & No data & No data & No data \\
\hline \multirow[t]{2}{*}{ Background } & 0.406 & 0.371 & 0.451 & 0.288 & 0.299 & 0.582 & 0.466 & 0.355 & 0.389 & 0.488 & 0.328 \\
\hline & \multicolumn{11}{|c|}{$P 3 / P 4$} \\
\hline Whole screen & $0.522^{\mathrm{a}}$ & $0.404^{\mathrm{b}}$ & $0.520^{\mathrm{a}}$ & $0.358^{\mathrm{c}}$ & $0.346^{\mathrm{b}}$ & 0.432 & $0.636^{\mathrm{a}}$ & $0.648^{\mathrm{a}}$ & $0.612^{\mathrm{a}}$ & $0.485^{\mathrm{f}}$ & $0.305^{\mathrm{c}}$ \\
\hline Bilateral identical & $0.414^{\mathrm{e}}$ & 0.331 & 0.307 & $0.281^{b}$ & 0.274 & 0.387 & $0.565^{\mathrm{a}}$ & $0.627^{\mathrm{a}}$ & 0.412 & No data & 0.242 \\
\hline Bilateral different & $0.435^{b}$ & $0.330 / 0.355$ & $0.279^{\mathrm{e}}$ & $0.284^{\mathrm{b}}$ & 0.286 & 0.363 & $0.496^{\mathrm{a}}$ & $0.525^{\mathrm{a}} / 0.572^{\mathrm{a}}$ & $0.391 / 0.419$ & 0.390 & No data \\
\hline Left & $0.416^{\mathrm{e}}$ & No data & 0.332 & $0.275^{\mathrm{b}}$ & 0.284 & 0.398 & No data & No data & No data & No data & No data \\
\hline Right & $0.406^{\mathrm{e}}$ & No data & 0.296 & $0.298^{f}$ & 0.267 & 0.398 & No data & No data & No data & No data & No data \\
\hline \multirow[t]{2}{*}{ Background } & 0.365 & 0.345 & 0.326 & 0.221 & 0.280 & 0.395 & 0.367 & 0.332 & 0.398 & 0.393 & 0.228 \\
\hline & \multicolumn{11}{|c|}{ T5/T6 } \\
\hline Whole screen & $0.278^{\mathrm{d}}$ & $0.221^{\mathrm{e}}$ & $0.338^{\mathrm{a}}$ & 0.213 & 0.219 & 0.331 & $0.376^{\mathrm{a}}$ & $0.376^{\mathrm{a}}$ & $0.451^{\mathrm{a}}$ & $0.348^{\mathrm{e}}$ & 0.194 \\
\hline Bilateral identical & 0.184 & 0.184 & 0.204 & 0.206 & 0.184 & 0.243 & $0.320^{\mathrm{a}}$ & $0.342^{\mathrm{a}}$ & 0.171 & No data & 0.164 \\
\hline Bilateral different & 0.206 & $0.183 / 0.167$ & 0.220 & 0.215 & 0.199 & 0.295 & 0.264 & $0.289 / 0.291$ & $0.163 / \mathbf{0 . 2 1 1}^{\mathrm{b}}$ & 0.294 & No data \\
\hline Left & 0.209 & No data & 0.200 & 0.194 & 0.198 & 0.304 & No data & No data & No data & No data & No data \\
\hline Right & 0.221 & No data & 0.165 & 0.215 & 0.178 & 0.300 & No data & No data & No data & No data & No data \\
\hline Background & 0.212 & 0.192 & 0.203 & 0.183 & 0.187 & 0.333 & 0.228 & 0.236 & 0.157 & 0.293 & 0.178 \\
\hline
\end{tabular}

The data are based on 2-s epochs of analysis. Significance levels are given compared to background values for the frequency band $25-46 \mathrm{~Hz} .{ }^{\text {a }} P<0.0000$. ${ }^{\mathrm{b}} P<0.01 .{ }^{\mathrm{c}} P<0.0005$. ${ }^{\mathrm{d}} P<0.005$. ${ }^{\mathrm{e}} P<0.05 .{ }^{\mathrm{f}} P<0.001$. The slash is used to separate values for the 2 bilateral different conditions, if applied. Left and right stand for stimuli presented in the left and right hemifields, respectively. ICoh, interhemispheric coherence.

the EEG signal in the alpha and gamma bands. To determine whether the spectral power was affected by the stimulation condition (whole screen, identical-close and different-close), we applied the nonparametric Friedman test (see METHODS, Statistical analysis) separately to the group data from each EEG derivation and band. Figure 6 shows that the decrease in the alpha power was similar for all the conditions in all derivations, whereas the increase in the gamma SPD was stimulus-specific in the occipital $(P=0.040$ for $\mathrm{O} 1$ and 0.028 for O2) and parietal ( $P=0.054$ for P3 and 0.069 for P4) derivations.

Pairwise comparisons of the responses confirmed that, in the gamma band, the whole-screen stimulus was accompanied by a significantly larger SPD response than any of the other stimulation conditions ( $P$ ranged from 0.006 to 0.035 for $\mathrm{O} 1, \mathrm{O} 2$, and $\mathrm{P} 4$, and increased up to 0.08 for $\mathrm{P} 3$, Wilcoxon test).

As mentioned above, both ICoh and SPD in the gamma band increased specifically with whole screen stimulation. In principle, the power spectra of two EEG signals do not determine their coherence spectrum, which depends also on their phase relations (Nunez 1995), and one can thus expect these two measures to vary independently. However, if the processing of a stimulus involves both locally and distantly distributed synchronizations at the same frequencies, an increase in both local power and in distant coherence should be observable. The scatterplots from Fig. 7 show that the association in question may be expected for the whole screen stimulus. Indeed, Pearson's correlations between SPD and ICoh responses appeared to be significant (at the $P=0.01$ level; 2-tailed) for the whole screen condition only ( 0.915 for $\mathrm{O} 1,0.936$ for $\mathrm{O} 2,0.845$ for $\mathrm{P} 3$, and 0.944 for P4).
D I S C U S S I O N

This study was designed to determine whether functional aspects of the cortico-cortical connectivity could be analyzed in humans with EEG coherence techniques. Our results show that in humans, as in animals (Kiper et al. 1999), the EEG ICoh responses are location, frequency, and stimulus specific. Comparison with animal data suggests that, in humans, callosal fibers can synchronize the activity in the two hemispheres, and, possibly, within the hemisphere. Indeed, we found that the gamma activity of visual areas in the two hemispheres becomes synchronized only when a subject views a stimulus that presumably activates callosal connectivity.

\section{Topography and frequency characteristics of the EEG ICoh response to visual stimulation}

Pronounced and reproducible ICoh responses, consistent across montage schemes, were restricted to occipital and parietal derivations (or parieto-occipital for bipolar EEG signals). This suggests that the responses resulted from the activity of the neural circuits underlying the posterior scalp electrodes. In addition, the observed changes in ICoh were visual stimulus dependent, and these changes conformed to predictions (see Kiper et al. 1999) based on the properties of the callosal connections between the visual areas of the two hemispheres. This points to the visual cortex as the main source of the activity we recorded in these experiments.

The surface electrode locations can be only roughly correlated with underlying cortical areas (Binnie et al. 1982; Myslobodsky and Bar-Ziv 1989). In particular, occipital electrodes $\mathrm{O} 1$ and $\mathrm{O} 2$, which are located lateral and superior to the occipital pole and overlapping the calcarine sulcus, might be either over Brodmann's area 17/V1, or 18/V2 (Homan et al. 1987). They might also record 

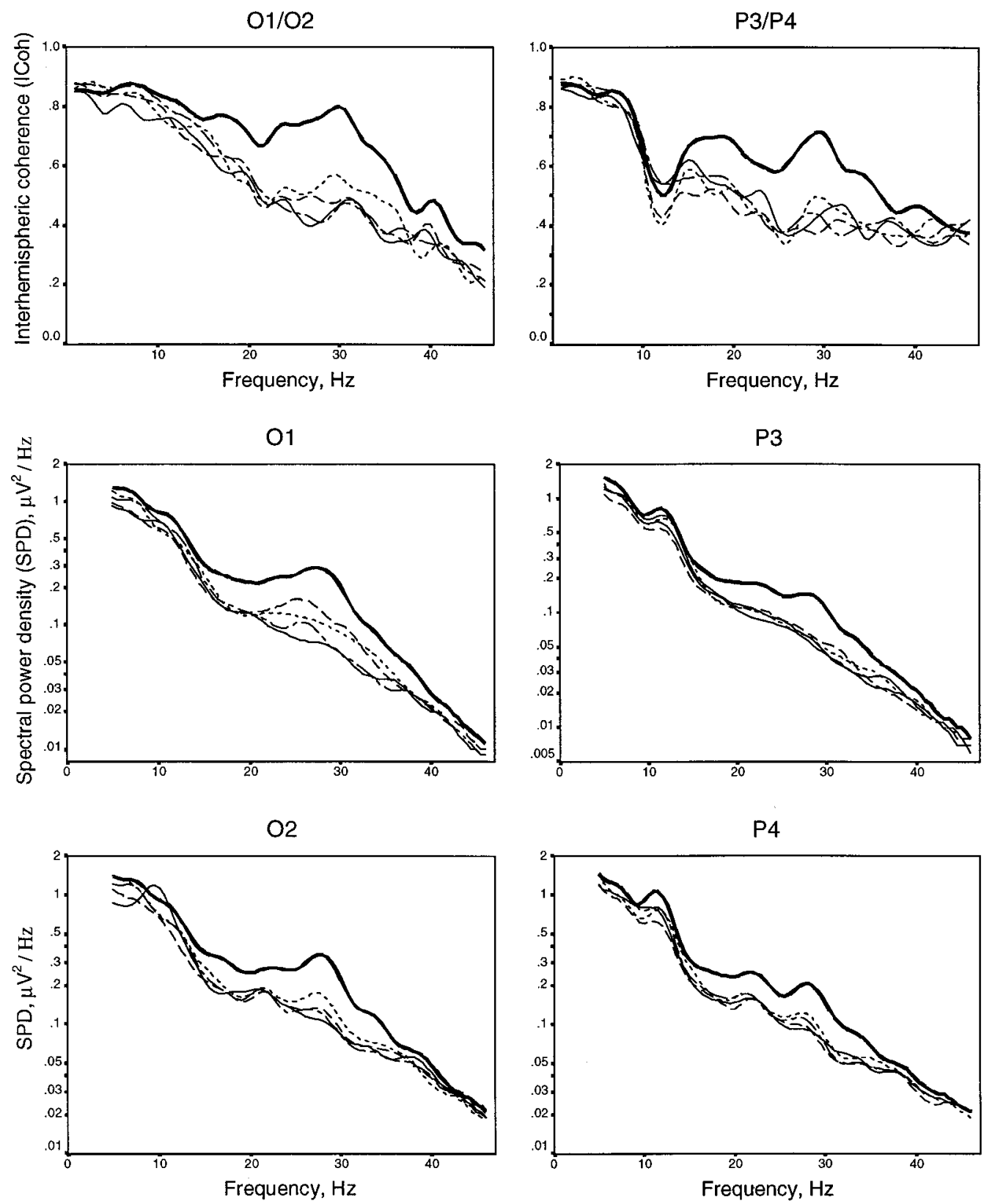

\section{Whole screen identical}

\section{Background}

Different close

FIG. 2. Individual ICoh (top 2 panels) and power spectra (bottom 4 panels) for subject $K L$ during various stimulation conditions: background (thin line), whole screen identical (thick line), whole screen different (dotted line), different close (dashed line), and identical close (dashed and dotted line).

the activity of other occipital extrastriate areas, because neuroimaging studies have shown that regions activated by coherently moving stimuli are considerably larger than primary visual areas (Van Essen and Drury 1997; Zeki 1993), and, in humans, callosal fibers connect both primary and secondary visual areas (Innocenti 1986; Zilles and Clarke 1997).

The P3 and P4 electrodes are localized over the parietal cortex, which is known to be concerned with visual functions (for reviews see Cavada and Goldman-Rakic 1993; Gulyás 1997). In particular, these locations were shown to occupy a portion of the superior parietal lobule (Brodmann's area 7), in the vicinity of the intraparietal sulcus (Homan et al. 1987). In primates, portions of area 7 are visually responsive (Johnson et al. 1993; Mouncastle et al. 1975; Steinmetz et al. 1987), and, in humans, this region may partially include the motion-selective area V3A (Tootell et al. 1997). 
TABLE 2. Individual ICoh values in the gamma band during visual stimulation with close gratings compared to the whole screen stimulus

\begin{tabular}{|c|c|c|c|c|c|c|c|c|c|c|c|}
\hline Stimuli & $I C$, Experiment 1 & $I C$, Experiment 2 & $N G$ & $D K$ & $L M$ & $L T$ & $N B$, Experiment 1 & $N B$, Experiment 2 & $K L$ & $M G$ & $T R$ \\
\hline & \multicolumn{11}{|c|}{$O 1 / O 2$} \\
\hline Bilateral identical & $0.432^{\mathrm{a}}$ & $0.381^{\mathrm{b}}$ & $0.457^{\mathrm{a}}$ & $0.315^{\mathrm{c}}$ & $0.294^{\mathrm{d}}$ & 0.559 & $0.678^{\mathrm{a}}$ & 0.568 & $0.415^{\mathrm{a}}$ & No data & $0.338^{\mathrm{a}}$ \\
\hline Bilateral different & $0.486^{\mathrm{d}}$ & $0.382^{\mathrm{b}} / 0.386^{\mathrm{e}}$ & $0.455^{\mathrm{a}}$ & 0.352 & $0.313^{\mathrm{e}}$ & 0.545 & $0.605^{\mathrm{a}}$ & $0.481^{\mathrm{a}} / 0.501^{\mathrm{a}}$ & $0.438^{\mathrm{a}} / 0.479^{\mathrm{a}}$ & $0.523^{\mathrm{d}}$ & No data \\
\hline Left & $0.458^{\mathrm{a}}$ & No data & $0.476^{\mathrm{a}}$ & $0.321^{\mathrm{b}}$ & $0.289^{\mathrm{d}}$ & 0.540 & No data & No data & No data & No data & No data \\
\hline Right & $0.458^{\mathrm{a}}$ & No data & $0.429^{\mathrm{a}}$ & $0.329^{\mathrm{b}}$ & $0.293^{\mathrm{c}}$ & 0.550 & No data & No data & No data & No data & No data \\
\hline \multirow[t]{2}{*}{ Whole screen } & 0.575 & 0.433 & 0.595 & 0.381 & 0.381 & 0.581 & 0.765 & 0.587 & 0.701 & 0.599 & 0.423 \\
\hline & \multicolumn{11}{|c|}{ P3/P4 } \\
\hline Bilateral identical & $0.414^{\mathrm{a}}$ & $0.331^{\mathrm{c}}$ & $0.307^{\mathrm{a}}$ & $0.281^{\mathrm{c}}$ & $0.274^{\mathrm{c}}$ & 0.387 & $0.565^{\mathrm{d}}$ & 0.627 & 0.412 & No data & $0.242^{\mathrm{d}}$ \\
\hline Bilateral different & $0.435^{\mathrm{d}}$ & $0.330^{\mathrm{c}} / 0.355^{\mathrm{e}}$ & $0.279^{\mathrm{a}}$ & $0.284^{\mathrm{c}}$ & $0.286^{\mathrm{e}}$ & $0.363^{\mathrm{b}}$ & $0.496^{\mathrm{a}}$ & $0.525^{\mathrm{a}} / 0.572^{\mathrm{a}}$ & $0.391^{\mathrm{a}} / 0.419^{\mathrm{a}}$ & $0.390^{\mathrm{d}}$ & No data \\
\hline Left & $0.416^{\mathrm{a}}$ & No data & $0.332^{\mathrm{a}}$ & $0.275^{\mathrm{d}}$ & $0.284^{\mathrm{b}}$ & 0.398 & No data & No data & No data & No data & No data \\
\hline Right & $0.406^{\mathrm{a}}$ & No data & $0.296^{\mathrm{a}}$ & $0.298^{\mathrm{c}}$ & $0.267^{\mathrm{f}}$ & 0.398 & No data & No data & No data & No data & No data \\
\hline \multirow[t]{2}{*}{ Whole screen } & 0.522 & 0.404 & 0.520 & 0.358 & 0.346 & 0.432 & 0.636 & 0.648 & 0.612 & 0.485 & 0.305 \\
\hline & \multicolumn{11}{|c|}{ T5/T6 } \\
\hline Bilateral identical & $0.184^{\mathrm{a}}$ & $0.184^{\mathrm{b}}$ & $0.204^{\mathrm{a}}$ & 0.206 & $0.184^{\mathrm{b}}$ & 0.343 & $0.320^{\mathrm{e}}$ & 0.342 & $0.171^{\mathrm{a}}$ & No data & $0.164^{\mathrm{b}}$ \\
\hline Bilateral different & $0.206^{\mathrm{d}}$ & $0.183^{\mathrm{b}}$ & $0.220^{\mathrm{a}}$ & 0.215 & 0.199 & 0.295 & $0.264^{\mathrm{a}}$ & $0.289^{\mathrm{d}} / 0.291^{\mathrm{a}}$ & $0.163^{\mathrm{a}} / 0.211^{\mathrm{a}}$ & $0.294^{\mathrm{e}}$ & No data \\
\hline Left & $0.209^{\mathrm{d}}$ & No data & $0.200^{\mathrm{a}}$ & 0.194 & 0.198 & 0.304 & No data & No data & No data & No data & No data \\
\hline Right & $0.221^{\mathrm{c}}$ & No data & $0.165^{\mathrm{a}}$ & 0.215 & $0.178^{\mathrm{b}}$ & 0.300 & No data & No data & No data & No data & No data \\
\hline Whole screen $t$ & 0.278 & 0.221 & 0.338 & 0.213 & 0.219 & 0.331 & 0.376 & 0.376 & 0.451 & 0.348 & 0.194 \\
\hline
\end{tabular}

${ }^{\mathrm{a}} P<0.0000 .{ }^{\mathrm{b}} P<0.05 .{ }^{\mathrm{c}} P<0.005 .{ }^{\mathrm{d}} P<0.0005 .{ }^{\mathrm{e}} P<0.01 .{ }^{\mathrm{f}} P<0.001$.

In five subjects, the response extended to posterior temporal derivations. The posterior temporal electrode over the left hemisphere (T5) falls on Brodmann's area 37, whereas on the right side (T6), it may be either over areas 19, 37, or 39 (Homan et al. 1987). Because we used moving stimuli, a more consistent response at T5 and T6 electrodes could have been expected because they are the closest to the presumptive motion associated visual area MT (Kaas 1995; Roland 1993; Tootell 1995; Van Essen and Drury 1997). However, considering the small size of this area, and inevitable differences in area and electrode location between subjects, the instability of the ICoh response in these electrodes is not surprising.

Of all the EEG rhythmic components, the alpha $(8-12 \mathrm{~Hz})$ and higher frequencies are considered mainly of cortical origin (Lopes da Silva 1991; Steriade et al. 1990). The alpha rhythms are viewed as a reflection of a "resting" state of the cortical areas (for review see Niedermeyer 1993; Pfurtscheller et al. 1996). Active states, such as the perception of visual stimuli, are accompanied by a desynchronization in the alpha-range (Lehtonen and Lehtinen 1972; Pfurtscheller et al. 1994; Ray and Cole 1985; Vanni et al. 1997). Consistent with this view, we observed a decreased power in the alpha band during visual stimulation with gratings, compared with the uniformly illuminated screen. In humans, interhemispheric synchronization in the alpha band was shown to be dependent on the integrity of the corpus callosum (CC) in the resting state (Koeda et al. 1995; Pinkofsky et al. 1997). In our experiments, ICoh in the alpha band tended to decrease or remained unchanged with visual stimulation. When an occasional increase was present, it appeared to be a component of a broadband response that involved the gamma frequencies as well. In addition, all changes in ICoh within this band were not stimulus specific.

Several human EEG studies revealed early-onset responses to visual stimuli in the gamma band. Lutzenberger et al. (1995) found an increase in the power of the $35-$ to $45-\mathrm{Hz}$ band within the first $500 \mathrm{~ms}$ of stimulation. It was obtained with horizontal bars moving coherently in the right and left quadrants of the upper or lower hemifield. A significant increase in the power at
$40-96 \mathrm{~Hz}$ was obtained by Müller et al. (1996), in response to a single vertical moving bar in the left hemifield, but not to two incoherently moving bars. The responses were predominantly from within the right hemisphere $(\mathrm{O} 2, \mathrm{P} 4, \mathrm{~T} 6$ locations) and were most pronounced between 400 and $900 \mathrm{~ms}$ after the motion onset. Finally, recent studies using static visual stimuli (Tallon et al. 1995; Tallon-Baudry et al. 1997) revealed a short-lived gamma response to a real or illusory object. The gamma response was widely distributed over the cortex, covering both postcentral and precental areas. These studies support the notion that the gamma band dynamics is associated with perception in humans, as it was originally suggested in animal studies (reviewed in Pulvermüller et al. 1997), but they cannot be interpreted in terms of cortical circuitry.

\section{Activation of callosal connections increases interhemispheric and, possibly, intrahemispheric synchronization}

Results presented in the companion paper (Kiper et al. 1999) suggested that callosal connections between areas 17, 18, and, possibly, 19 of the two hemispheres, when activated by a visual stimulus, synchronized the gamma band activity of these areas. These conclusions were based on three aspects of the results. First, the activation was obtained by stimuli located close to the VM of the visual field, whose representations are selectively connected by the CC, not for more peripheral stimuli. Second, the activation was obtained with bilateral iso-oriented gratings, but not with gratings of different orientation. Finally, the effects were eliminated by transection of the $\mathrm{CC}$, as is also the case for the correlated activity of single neurons (Engel et al. 1991).

In humans, as in other species (reviewed in Innocenti 1986; Kennedy et al. 1991), the representations of the VM of the visual field are selectively interconnected by callosal axons in the primary and in some of the secondary visual areas (Clarke and Miklossy 1990). Therefore by comparison with the animal work, the present results suggest that the increased coherence in the gamma band is due to activation of callosal connections, 

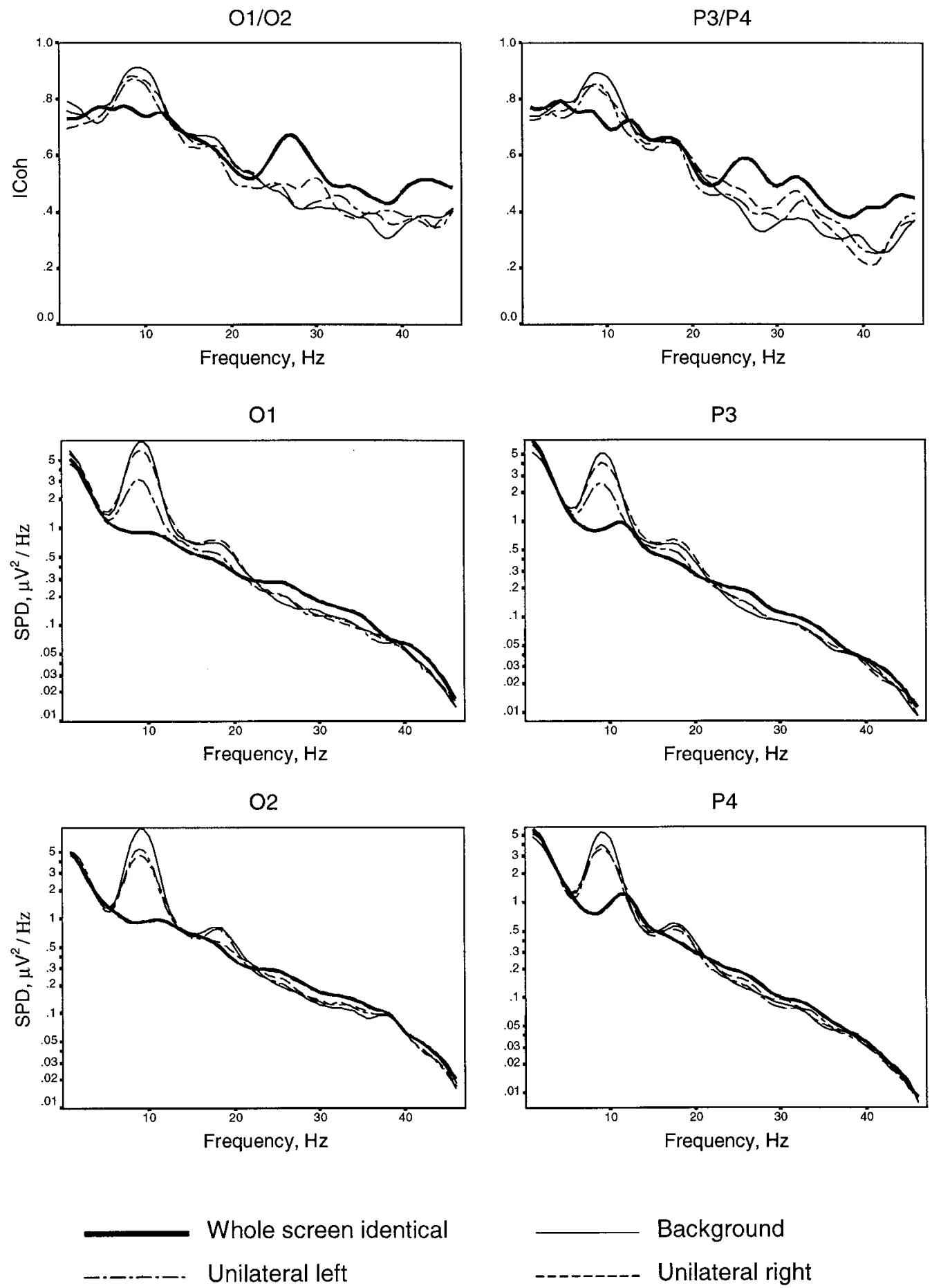

FIG. 3. Individual ICoh and power spectra (subject IC) associated with the unilateral visual stimuli: left, i.e., with the stimulus located in the left visual hemifield (dashed and dotted line), and right (dashed line). Results for the whole screen identical (thick line) and background (thin line) stimuli are shown for comparison.

which probably interconnect exclusively or preferentially isoorientation columns (Gilbert and Wiesel 1989; discussed in Houzel et al. 1994). Whether callosal axons selectively interconnect iso-orientation columns in primates is not known, although a columnar organization of callosal connections was demonstrated in monkeys (Kennedy et al. 1986). It is tempting to assume that callosal axons do selectively interconnect isoorientation columns in man. This might be a general trait of cortico-cortical connectivity implementing "collinearity," a fundamental principle of "Gestalt" perception (Bosking et al. 1997; Schmidt et al. 1997). Unlike in our animal study, we do not know whether the transection of the $\mathrm{CC}$ would eliminate the stimulus-dependent interhemispheric synchronization of gamma activity in humans. This is likely, however, because recent studies support a role of callosal connections in synchronizing the activity of the two hemispheres in humans 
01/O2

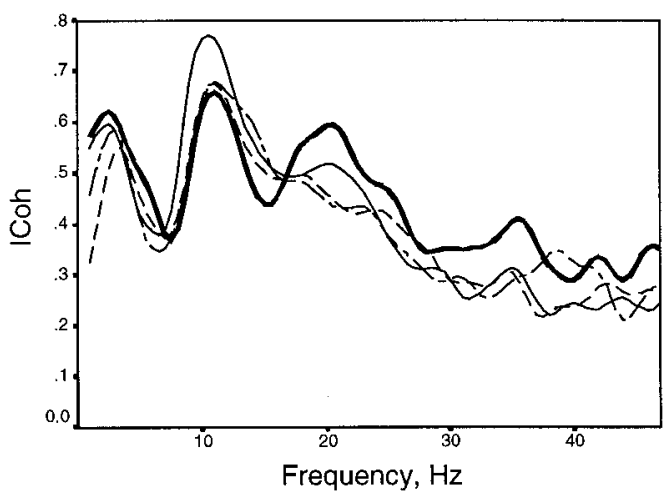

01

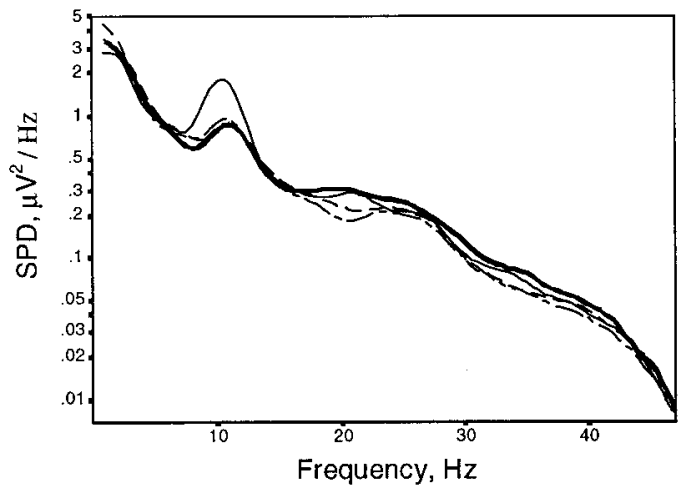

$\mathrm{O} 2$
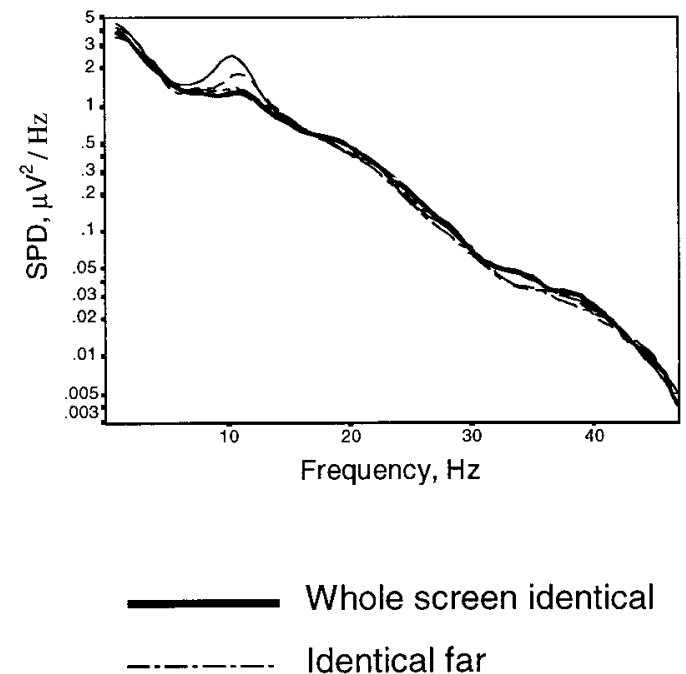

P3/P4

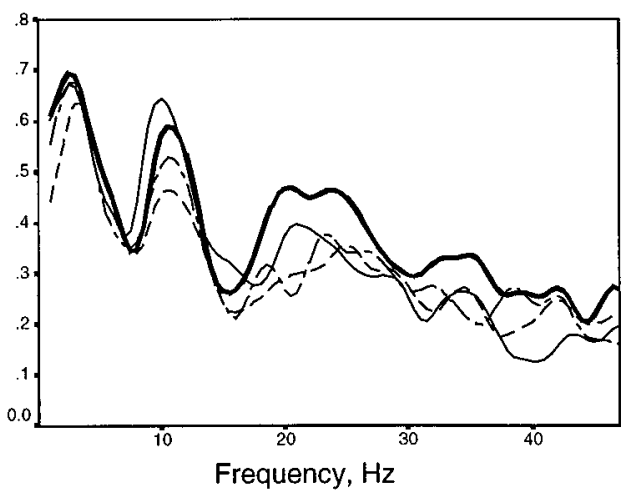

P3

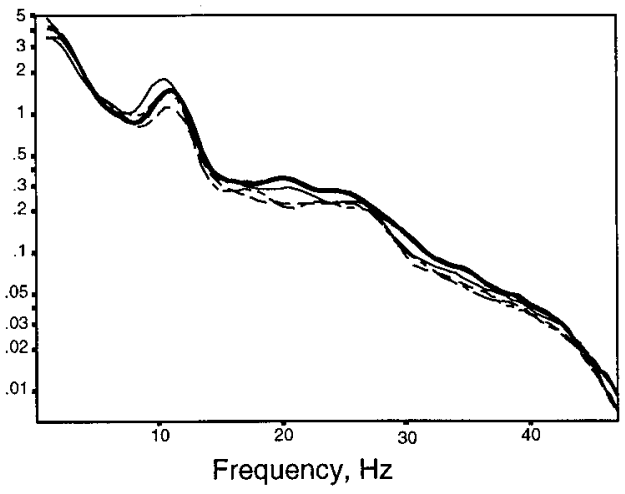

P4

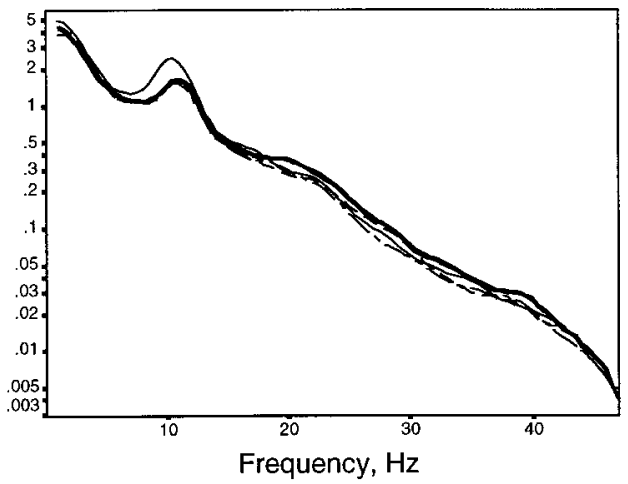

Background

\section{Different far}

FIG. 4. Individual ICoh and power spectra (subject $L M$ ) associated with visual stimuli presented far from the vertical meridian: identical far (dashed and dotted line), and different far (dashed line) stimuli. The background (thin line) and whole screen identical (thick line) conditions are shown for comparison.

(Koeda et al. 1995). A study in split-brain patients could help to rule out the possibility that, in spite of our precautions, volume conduction could contribute to the stimulus-dependent ICoh dynamics.

There is one important difference between our animal and human results. In the animal experiments, EEG coherence increased with stimuli separated $2.6^{\circ}$ from the VM. In humans, instead, it increased only with stimuli extending across the VM. One possible explanation of these differences is that the callosal connections cover a narrower strip of visual field representation in man than in ferret. Furthermore, a complete activation of the region of bilateral representation in the cortex might be required. This region was estimated to extend $\sim 1^{\circ}$ on either side of the VM (Fendrich et al. 1996), and therefore only half of it was stimulated by the bilateral identical stimuli. Alternatively, in awake humans, ICoh might increase only when the stimuli are perceived as a whole, rather than two separate gratings (Kiper et al. 1998; Knyazeva et al. 1998). 

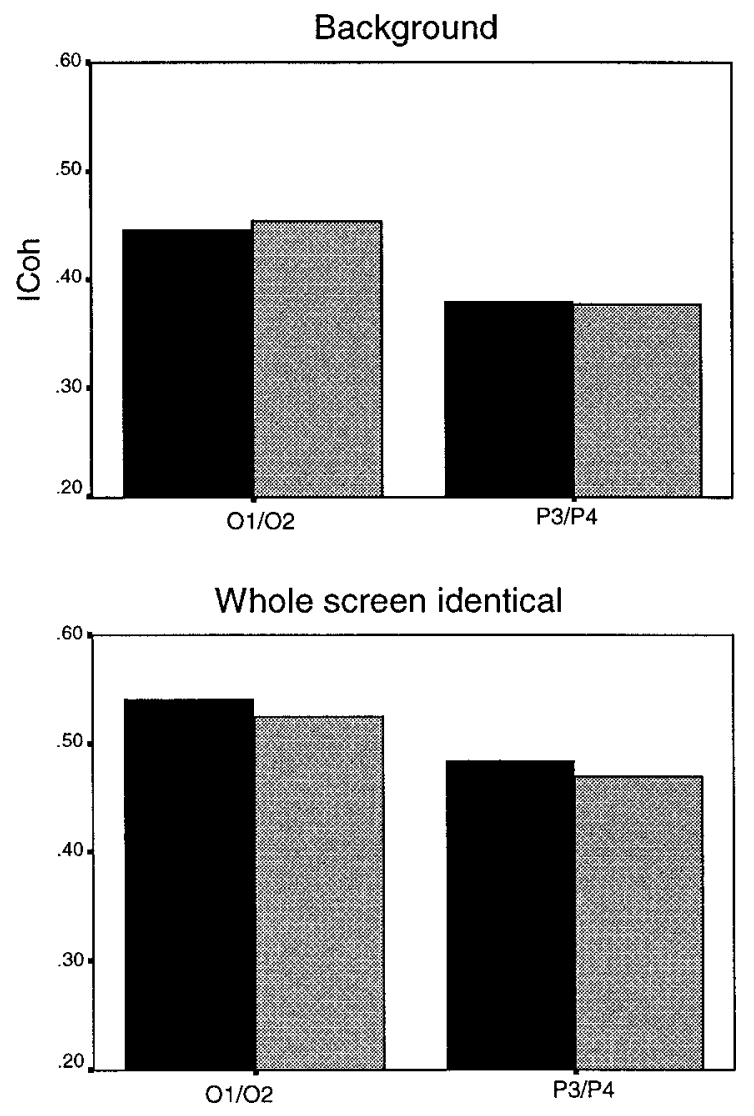

First $1 \mathrm{sec}$

Last $1 \mathrm{sec}$

FIG. 5. Bars represent group ICoh values for the 1st and 2nd second of stimulation period.

The same explanation relates to the question of the functional significance of the increased coherence in the gamma band. Assuming that the synchronicity of activity serves as a "tag" for perceived "connectedness" across cortical networks, the occurrence of oscillations in the gamma band is currently interpreted as a way of the temporal tag spreading (Roelfsema and Singer 1998). If this is true, and, if the callosal connections are critical in propagating the tag, one would predict errors in perceiving connectedness when callosal connections are interrupted. The rich literature on split-brain and acallosal subjects provides evidence in favor of such a conclusion. Indeed, each hemisphere of a split-brain patient can erroneously complete its own version of incomplete or chimeric figures flashed along the VM (Levy et al. 1972; reviewed in Trevarthen 1990). Furthermore, a patient's performance in judging the alignment of two lines is degraded when these are flashed to separate hemispheres. Also, the patients cannot perform lexical decision on letters divided between the two hemifields and perform poorly on other tasks requiring interactions between the two hemispheres (reviewed in Corballis 1995). In addition, split brain or acallosal patients are impaired in the stereoscopic vision along the VM (Lassonde et al. 1995; Mitchell and Blakemore 1970), a low level type of cortical binding, for which the role of the CC is debated (reviewed in Berlucchi and Antonini 1990).

With the limitations mentioned, it appears that changes in interhemispheric EEG coherence can probably be used to assay electrophysiologically the functionality of callosal connections. Therefore this method complements others such as the psychophysical study of the interference between gratings presented near the VM (Berardi et al. 1989), the analysis of ipsilaterally evoked responses (Brown et al. 1994), and transcranial magnetic stimulation (Paus et al. 1997).

It should be mentioned that anatomic studies in the cat and computer simulations predicted that callosal connections would play a role not only in the synchronization of activity between the two hemispheres, but also on the local activity within each hemisphere (Innocenti et al. 1994). The prediction seems to be borne out in the present study because the whole screen condition not only increased the distant interhemispheric synchronization, but also the EEG power in the gamma band. It was previously shown that an increase in the EEG power is indicative of local synchronization of the postsynaptic potentials in the vicinity of the recording electrode (Creutzfeldt et al. 1966). However, a comparable increase in the EEG power was not obtained in our animals study (Kiper et al. 1999). The reasons for this difference are not known. It may be due to the effect of anesthesia in the animal work, or to

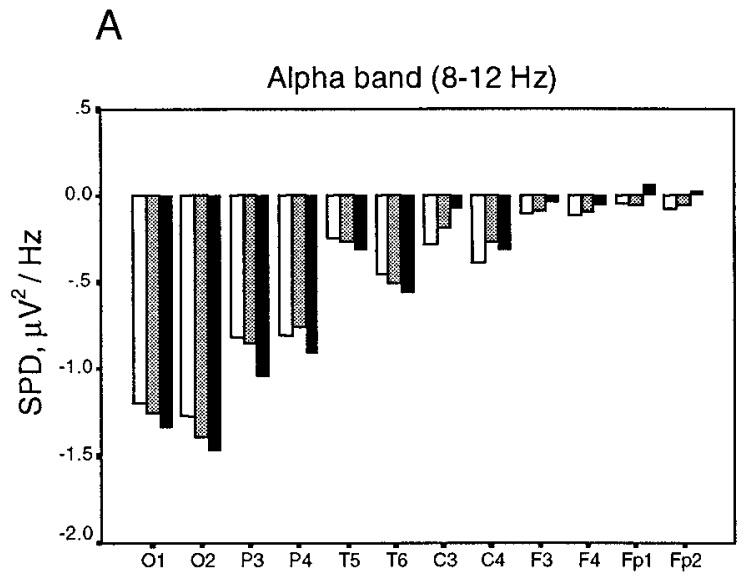

$\mathrm{B}$

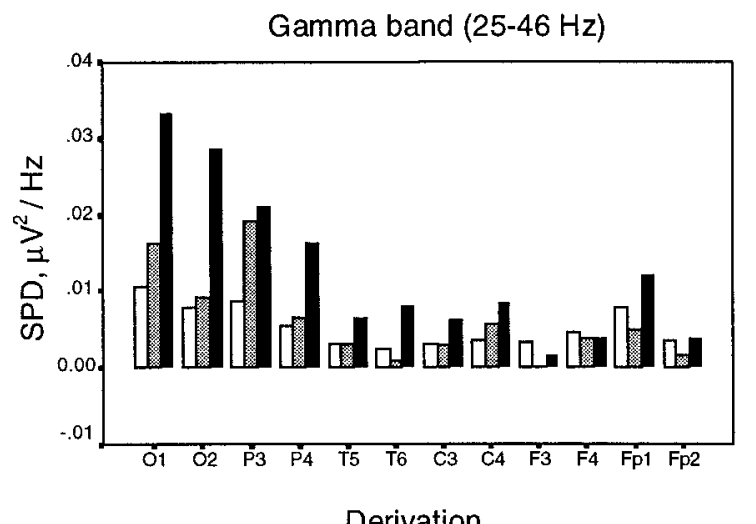

Derivation

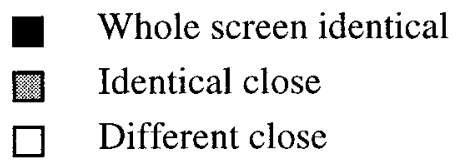

FIG. 6. Group averaged power spectra in the alpha $(A)$ and gamma $(B)$ bands to the whole screen identical, different close, and identical close stimuli. 


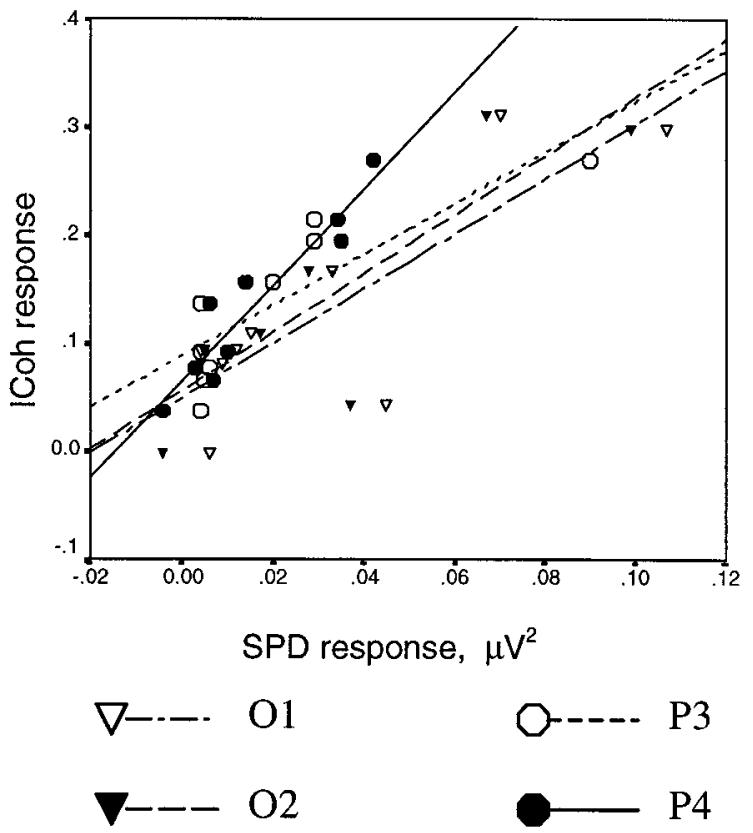

FIG. 7. Scatterplot of ICoh and spectral power density (SPD) responses in the gamma band obtained from the occipital ( $\nabla$ and $\boldsymbol{\nabla})$ and parietal $(\bigcirc$ and $\bullet$ ) EEG derivations. Each data point represents a single subject's response to the whole screen identical stimulus.

differences in the functional callosal connectivity between ferrets and man.

\section{Possible mechanisms of callosal action}

How activation of callosal connections modifies the synchronous activity in the hemispheres remains unclear. One obvious possibility is that the activity in callosal axons can, on its own, control the activity of the postsynaptic targets. This is consistent with observations in split-chiasm cats (Berlucchi and Rizzolatti 1968; Milleret et al. 1994; Tardif et al. 1997), and with the fact that callosally projecting neurons can display oscillatory activity (Nunez et al. 1992). However, in our experimental conditions, the stimulation of one hemifield, with gratings extending near the $\mathrm{VM}$, and, therefore presumably activating the callosally projecting neurons, was insufficient to modify the interhemispheric coherence and to increase the local power in the gamma band. This relative weakness of the callosal input is compatible with recent morphometric observations, stressed relative inadequacy of the callosal compared with thalamocortical axons to drive the postsynaptic targets (Tettoni et al. 1998). As an alternative to the direct drive explanation, it could be suggested that the activity of the two hemispheres synchronizes when two conditions are present: 1 ) direct thalamic input to the two hemispheres and 2) reverberating activation between the hemispheres. A neural network embodying such features did in fact generate synchronous oscillations in the two hemispheres, albeit in the theta rhythm (Innocenti et al. 1995). Gamma oscillations might be generated when callosal input, adding to the thalamocortical input, brings the depolarization of the callosally projecting neurons and/or their targets to a sufficient level of depolarization to trigger their intrinsic rhythm (Gray and McCormick 1996; Steriade 1997). This interpretation is compatible with the many electrophysiological observations demonstrating that the $\mathrm{CC}$ in- creases cortical excitability (Berlucchi 1966; Bremer et al. 1956; Innocenti 1986). In particular, Bremer (1967) showed that evoked potentials in the cat visual cortex increased in amplitude if preceded by stimulation of the homotopic area in the contralateral hemisphere. Creutzfeldt et al. (1969) reported synchronous excitation of the neurons in superficial cortical layers in the case of contralaterally evoked callosal potential. This effect disappeared after section of the CC. Obviously, the fact that the activity of callosal connections may be limited to facilitatory influences in certain conditions does not imply that it is, by itself, never sufficient to drive the postsynaptic targets. One appealing possibility is that the callosal and other corticocortical connections can switch from a feed-forward mode to an assembly creating mode, the latter revealed by the appearance of gamma oscillations.

We thank the technicians in the EEG department at the Centre Hospitalier Universitaire Vaudois for precious help during the recording sessions. We are also grateful to the Institut de Biologie Cellulaire et de Morphologie staff members who agreed to participate in this study as subjects.

This research was supported by PNR38 Grant 4038-043990 of the Swiss National Science Foundation.

Address for reprint requests: G. M. Innocenti, Division of Neuroanatomy and Brain Development, Dept. of Neuroscience, Karolinska Institutet, S-17177 Stockholm, Sweden.

Received 14 December 1998; accepted in final form 9 August 1999.

\section{REFERENCES}

Andrew, C. And Pfurtscheller, G. Dependence of coherence measurement on EEG derivation type. Med. Biol. Eng. Comput. 34: 232-238, 1996.

Berardi, N., Bodis-Wollner, I., Fiorentini, A., Giuffré, G., AND Morelli, M. Electrophysiological evidence for interhemispheric transmission of visual information in man. J. Physiol. (Lond.) 411: 207-225, 1989.

BERLUCCHI, G. Electroencephalographic studies in "split brain" cats. Electroencephalogr. Clin. Neurophysiol. 20: 348-356, 1966.

BERLUCCHI, G. AND ANTONINI, A. The role of the corpus callosum in the representation of the visual field in cortical areas. In: Brain Circuits and Functions of the Mind. Essays in Honour of R. W. Sperry, edited by C. Trevarthen. Cambridge, UK: Cambridge Univ. Press, 1990, p. 129-139.

BERLUCCHI, G. AND RIZZOLATTI, G. Binocularly driven neurons in visual cortex of split-chiasm cats. Science 159: 308-310, 1968.

Binnie, C. D., Dekker, E., Smit, A., and Van der Linden, G. Practical considerations in the positioning of EEG electrodes. Electroencephalogr. Clin. Neurophysiol. 53: 453-458, 1982.

Bosking, W. H., Zhang, Y., Schofield, B., and FitzPatrick, D. Orientation selectivity and the arrangement of horizontal connections in tree shrew striate cortex. J. Neurosci. 17: 2112-2127, 1997.

BREMER, F. La physiologie du corps calleux a la lumiere de travaux recents. Lav. Med. 38: 835-843, 1967.

Bremer, F., Brihaye, J., AND André-Balisaux, G. Physiologie et pathologie du corps calleux. Schweiz. Arch. Neurol. Psych. 78: 31-87, 1956.

Bressler, S. L., Coppola, R., And Nakamura, R. Episodic multiregional cortical coherence at multiple frequencies during visual task performance. Nature 366: 153-156, 1993.

Brown, W. S., Larson, E. B., AND JeEves, M. A. Directional asymmetries in interhemispheric transmission time: evidence from visual evoked potentials. Neuropsychologia 32: 439-448, 1994.

CACiOPPo, J. T., TAssinary, L. G., AND Friflund, A. The skeletomotor system. In: Principles of Psychophysiology. Physical, Social, and Inferential Elements, edited by J. T. Cacioppo and L. G. Tassinary. Cambridge, UK: Cambridge Univ. Press, 1990, p. 325-384.

Cavada, C. AND Goldman-Rakic, P. S. Multiple visual areas in the posterior parietal cortex of primates. Prog. Brain Res. 95: 123-137, 1993.

Clarke, S. AND MiKLossy, J. Occipital cortex in man: organization of callosal connections, related myelo- and cytoarchitecture, and putative boundaries of functional visual areas. J. Comp. Neurol. 298: 188-214, 1990.

Corballis, M. C. Visual integration in the split brain. Neuropsychologia 33: 937-959, 1995. 
Creutzfeldt, O. D., Maekawa, K., And Hösli, L. Forms of spontaneous and evoked post-synaptic potentials of cortical nerve cells. Prog. Brain Res. 31: 265-274, 1969.

Creutzfeldt, O. D., Watanabe, S., And Lux, H. D. Relation between EEG-phenomena and potentials of single cells. Part I and II. Electroencephalogr. Clin. Neurophysiol. 20: 1-37, 1966.

Desmedt, J. E. AND TomberG, C. Transient phase-locking of $40 \mathrm{~Hz}$ electrical oscillations in prefrontal and parietal human cortex reflects the process of conscious somatic perception. Neurosci. Lett. 168: 126-129, 1994.

ECKHORN, R. Oscillatory and non-oscillatory synchronizations in the visual cortex of cat and monkey. In: Oscillatory Event-Related Brain Dynamics, edited by C. Pantev, T. Elbert, and B. Lütkenhöner. New York: Plenum, 1994, p. 115-134.

Engel, A. K., König, P., Kreiter, A. K., Schillen, T. B., And Singer, W. Temporal coding in the visual cortex: new vistas on integration in the nervous system. Trends Neurosci. 15: 218-226, 1992.

Engel, A. K., König, P., Kreiter, A. K., AND Singer, W. Interhemispheric synchronization of oscillatory neuronal responses in cat visual cortex. Science 252: 1177-1179, 1991.

Fein, G., Raz, F. F., AND Merrin, E. L. Common reference coherence data are confounded by power and phase effects. Electroencephalogr. Clin. Neurophysiol. 69: 581-584, 1988.

FENDRICH, R., WeSSINGER, C. M., AND GAZZANIGA, M. S. Nasotemporal overlap at the retinal vertical meridian: investigations with a callosotomized patient. Neuropsychologia 34: 637-646, 1996.

GiBBS, E. L. AND GIBBS, T. J. Universal APEEGE (anatomical placement of EEG electrodes) system. Clin. Electroencephalogr. 15: 1-21, 1984.

Gilbert, C. D. AND WiESEL, T. N. Columnar specificity of intrinsic horizontal and corticocortical connections in cat visual cortex. J. Neurosci. 9: 24322442, 1989.

Gray, C. M. AND McCormick, D. A. Chattering cells: superficial pyramidal neurons contributing to the generation of synchronous oscillations in the visual cortex. Science 274: 109-113, 1996.

GulYás, B. Functional organization of human visual cortical areas. Cereb. Cortex 12: 743-775, 1997

HJoRTH, B. An on-line transformation of EEG scalp potentials into orthogonal source derivations. Electroencephalogr. Clin. Neurophysiol. 39: 526-530, 1975.

Homan, R. W., Herman, J., AND Purdy, P. Cerebral location of international 10-20 system electrode placement. Electroencephalogr. Clin. Neurophysiol. 66: 376-382, 1987.

Houzel, J. C., Milleret, C., AND InNocenti, G. Morphology of callosal axons interconnecting areas 17 and 18 of the cat. Eur. J. Neurosci. 6: 898-917, 1994.

INNOCENTI, G. M. General organization of callosal connections in the cerebral cortex. In: Cerebral Cortex, edited by E. G. Jones and A. Peters. New York: Plenum, 1986, vol. 5, p. 291-353.

InNocenti, G. M., Aggoun-Zouadou, D., And Lehmann, P. Cellular aspects of callosal connections and their development. Neuropsychologia 33: 961-987, 1995.

InNocenti, G. M., Lehmann, P., And Houzel, J. C. Computational structure of visual callosal axons. Eur. J. Neurosci. 6: 918-935, 1994

JASPER, H. H. The ten-twenty electrode system of the International Federation. Electroencephalogr. Clin. Neurophysiol. 10: 371-375, 1958.

Johnson, P. B., Ferraina, S., AND CAminiti, R. Cortical networks for visual reaching. Exp. Brain Res. 97: 361-365, 1993.

Joliot, M., RIBARY, U., AND LLINAS R. Human oscillatory brain activity near $40 \mathrm{~Hz}$ coexists with cognitive temporal binding. Proc. Natl. Acad. Sci. USA 91: $11748-11751,1994$.

Jürgens, E., Rosler, F., Henninghausen, E., and Heil, M. Stimulus-induced gamma oscillations: harmonics of alpha activity? NeuroReport 6: 813-816, 1995.

KaAS, J. H. Progress and puzzles. Curr. Biol. 5: 1126-1128, 1995.

Kelly, E. F., Lenz, J. E., Franaszczuk, P. J., and Truong, Y. K. A general statistical framework for frequency-domain analysis of EEG topographic structure. Comput. Biomed. Res. 30: 129-164, 1997.

Kennedy, H., Dehay, C., AND Bullier, J. Organization of the callosal connections of visual areas V1 and V2 in the macaque monkey. J. Comp. Neurol. 247: 398-415, 1986.

Kennedy, H., MeissiRel, C., And Dehay, C. Callosal pathways and their compliancy to general rules governing the organization of corticocortical connectivity. In: Vision and Visual Dysfunction. Neuroanatomy of the Visual Pathways and Their Development, edited by B. Dreher and S. Robinson. London: Macmillan, 1991, vol. 3, p. 324-359.
Kiper, D. C., Knyazeva, M. G., Tettoni, L., And Innocenti, G. M. Visual stimulus-dependent changes in interhemispheric EEG coherence in ferrets. J. Neurophysiol. 82: 3082-3094, 1999.

Kiper, D. C., Knyazeva, M. G., Tettoni, L., Maeder, M., and Innocenti, G. M. Interhemispheric EEG coherence during visual stimulation (Abstract). Invest. Opthalmol. Vis. Sci. 39: 324, 1998.

Knyazeva, M. G., Kiper, D. C., AND InNocenti, G. M. EEG coherence as a measure of functional connectivity: from experiment to human study (Abstract). Int. J. Psychophysiol. 30: 74, 1998.

Koeda, T., Knyazeva, M., Nuiokiktjien, C., Jonkman, E. J., De Sonneville, L., AND VILDAVsKy, V. The EEG in acallosal children. Coherence values in the resting state: left hemisphere compensatory mechanism? Electroencephalogr. Clin. Neurophysiol. 95: 397-407, 1995.

Kreiter, A. K. AND Singer, W. Oscillatory neuronal responses in the visual cortex of the awake macaque monkey. Eur. J. Neurosci. 4: 369-375, 1992.

KREITER, A. K. AND Singer, W. Stimulus-dependent synchronization of neuronal responses in the visual cortex of the awake macaque monkey. J. Neurosci. 16: 2381-2396, 1996.

Kristeva-Feige, R., Feige, B., Makeig, S., Ross, B., and Elbert, T. Oscillatory brain activity during a motor task. Neuroreport 4: 1291-1294, 1993.

Lassonde, M., Sauerwein, H. C., AND LePORE, F. Extent and limits of callosal plasticity: presence of disconnection symptoms in callosal agenesis. Neuropsychologia 33: 989-1007, 1995.

LEHMANN, D. Spatial analysis of the EEG and evoked potential data. In: Topographic Mapping of Brain Electrical Activity, edited by F. Duffy. Boston, MA: Butterworth, 1986, p. 29-61.

Lehtonen, J. B. AND Lehtinen, I. Alpha rhythm and uniform visual field in man. Electroencephalogr. Clin. Neurophysiol. 32: 139-147, 1972.

LeVy, J., Trevarthen, C., AND Sperry, R. W. Perception of bilateral chimeric figures following hemispheric deconnexion. Brain 95: 61-78, 1972.

LOPES DA Silva, F. N. Neural mechanisms underlying brain waves: from neural membranes to networks. Electroencephalogr. Clin. Neurophysiol. 79: 81-93, 1991

Lopes Da Silva, F. N., Van Lierop, T.H.M.T., SchriJer, C.F.M., AND Storm VAN LEEUWEN, W. Organization of thalamic and cortical alpha rhythms: spectra and coherences. Electroencephalogr. Clin. Neurophysiol. 35: 627639, 1973.

Lutzenberger, W., Preissl, H., Birbaumer, N., and Pulvermüller, F. High-frequency cortical responses: do they not exist if they are small? Electroencephalogr. Clin. Neurophysiol. 102: 64-66, 1997.

Lutzenberger, W., Pulvermüller, F., Elbert, T., and Birbaumer, N. Visual stimulation alters local $40-\mathrm{Hz}$ response in humans: an EEG study. Neurosci. Lett. 183: 39-42, 1995.

MAKEIG, S. Auditotory event-related dynamics of the EEG spectrum and effects of exposure to tones. Electroencephalogr. Clin. Neurophysiol. 86: 283-293, 1993.

Menon, V., Freeman, W. J., Cutillo, B. A., Desmond, J. E., Ward, M. F., Bressler, S. L., LaXer, K. D., Barbaro, N., and Jevins, A. S. Spatiotemporal correlations in human gamma band electrocorticograms. Electroencephalogr. Clin. Neurophysiol. 98: 89-102, 1996.

Milleret, C., Houzel, J. C., AND Buser, P. Pattern of development of the callosal transfer of visual information to cortical areas 17 and 18 in the cat. Eur. J. Neurosci. 6: 193-202, 1994.

Mitchell, D. E. and Blakemore, C. Binocular depth perception and the corpus callosum. Vision Res. 10: 49-54, 1970.

Morrison, D. F. Multivariate Statistical Methods (3rd ed.). New York: McGraw-Hill, 1990.

Mountcastle, V. B., Lynch, J. C., Georgopoulos, A., Sakata, H., and Acuna, C. Posterior parietal association cortex of the monkey: command functions for operations within extrapersonal space. J. Neurophysiol. 38: 871-908, 1975.

Müller, M. M., Bosch, J., Elbert, T., Kreiter, A., Sosa, M. V., Sosa, P. V., AND RocKSTROH, B. Visually induced gama-band responses in human electroencephalographic activity—a link to animal studies. Exp. Brain Res. 112: 96-102, 1996.

MunK, M.H.J., NowaK, L. G., Nelson, J. I., AND Bullier, J. Structural basis of cortical synchronization. II. Effects of cortical lesions. J. Neurophysiol. 74: 2401-2414, 1995.

MyslobodSKY, M. S. AND BAR-ZIV, J. Locations of occipital EEG electrodes verified by computed tomography. Electroencephalogr. Clin. Neurophysiol. 72: 362-366, 1989.

NIEDERMEYER, E. The normal EEG of the waking adult. In: Electroencephalography Basic Principles, Clinical Applications and Related Fields (3rd 
ed.), edited by E. Niedermeyer and F. Lopes da Silva. Baltimore, MD: Williams \& Wilkins, 1993, p. 131-152.

Nunez, A., AmziKa, F., ANd Steriade, M. Voltage-dependent fast $(20-40 \mathrm{~Hz})$ oscillations in long-axoned neocortical neurons. Neuroscience 51: 7-10, 1992.

NunEZ, P. Electric Fields of the Brain. New York: Oxford Univ., 1981.

NunEZ, P. Neocortical Dynamics and Human EEG Rhythms. New York: Oxford, 1995.

Nuwer, M. R., Lehmann, D., Lopes da Silva, F., Matsuoka, S., Sutherling, W., AND VIBERT, J.-F. IFCN guidelines for topographic and frequency analysis of EEGs and EPs. Report of an IFCN Committee. Electroencephalogr. Clin. Neurophysiol. 91: 1-5, 1994.

OsSELTON, J. W. Bipolar, unipolar and average reference recording methods. I. Mainly theoretical considerations. Am. J. EEG Technol. 6: 129-141, 1966.

OsSELTON, J. W. Bipolar, unipolar and average reference recording methods. II. Mainly practical considerations. Am. J. EEG Technol. 9: 117-133, 1969.

Pantev, C., Makeig, S., Hoke, M., Galambos, R., and Gallen, C. Human auditory evoked gamma-band magnetic fields. Proc. Natl. Acad. Sci. USA 88: 8996-9000, 1991.

Paus, T., Jech, R., Thompson, C. J., Comeau, R., Peters, T., and Evans, A. C. Transcranial magnetic stimulation during positron emission tomography: a new method for studying connectivity of the human cerebral cortex. J. Neurosci. 17: 3178-3184, 1997.

Pfurtscheller, G., NeuPer, C., AND Mohl, W. Event-related desynchronization during visual processing. Int. J. Psychophysiol. 16: 147-153, 1994.

Pfurtscheller, G., StancaK, A., JR., AND Neuper, C. Event-related synchronization (ERS) in the alpha band-an electrophysiological correlate of cortical idling: a review. Int. J. Psychophysiol. 24: 39-46, 1996.

Pinkofsky, H. B., Struve, F. A., Meyer, M. A., Patrick, G., and Reeves, R. R. Decreased multi-band posterior interhemispheric coherence with a lipoma on the corpus callosum: a case report of a possible association. Clin. Electroencephalogr. 28: 155-159, 1997.

Pulvermüller, F., Birbaumer, N., Lutzenberger, W., AND Mohr, B. Highfrequency brain activity: its possible role in attention, perception and language processing. Prog. Neurobiol. 52: 427-445, 1997.

Pulvermüller, F., Preissl, H., Lutzenberger, W., and Birbaumer, N. Spectral responses in the gamma-band: Physiological signs of higher cognitive processes? NeuroReport 6: 2059-2064, 1995.

RAY, W. J. AND COLE, H. W. EEG alpha activity reflects attentional demands, and beta activity reflects emotional and cognitive processes. Science 228: $750-752,1985$.

REILLY, E. L. EEG recording and operation of the apparatus. In: Electroencephalography. Basic Principles, Clinical Applications and Related Fields (3rd ed.), edited by E. Niedermeyer and F. Lopes da Silva. Baltimore, MD: Williams \& Wilkins, 1993, p. 104-124.

Roelfsema, P. R. And Singer, W. Detecting connectedness. Cereb. Cortex 8: 385-396, 1998

Roland, P. E. Brain Activation. New York: Wiley-Liss, 1993.

SANNITA, W. G. Retinal and cortical oscillatory responses to patterned and unpatterned visual stimulation in man. In: Oscillatory Event-Related Brain Dynamics, edited by C. Pantev, T. Elbert, and B. Lütkenhöner. New York: Plenum, 1994, p. 167-181

Sannita, W. G., Lopes, L., Piras, C., And Di Bon, G. Scalp-recorded oscillatory potentials evoked by transient pattern-reversal visual stimulation in man. Electroencephalogr. Clin. Neurophysiol. 96: 206-218, 1995.
Schmidt, K. E., Kim, D. S., Singer, W., Bonhoeffer, T., And Lowel, S. Functional specificity of long-range intrinsic and interhemispheric connections in the visual cortex of strabismic cats. J. Neurosci. 17: 5480-5492, 1997.

Singer, W. AND GRAY, C. M. Visual feature integration and the temporal correlation hypothesis. Аnпи. Rev. Neurosci. 18: 555-586, 1995.

Steinmetz, M. A., Motter, B. C., Duffy, C. J., And Mountcastle, V. B. Functional properties of parietal visual neurons: radial organization of directionalities within the visual field. J. Neurosci. 7: 177-191, 1987.

Steriade, M. Synchronized activities of coupled oscillators in the cerebral cortex and thalamus at different levels of vigilance. Cereb. Cortex 7: 583-604, 1997.

Steriade, M., Gloor, P., Llinas, R. R., Lopes da Silva, F., and Mesulam, M.-M. Basic mechanisms of basic rhythmic activities. Report of an IFCN Committee. Electroencephalogr. Clin. Neurophysiol. 76: 481-508, 1990.

Tallon, C., Bertrand, O., Bouchet, P., And Pernier, J. $\gamma$-Range activity evoked by coherent visual stimuli in humans. Eur. J. Neurosci. 7: 12851291,1995

Tallon-Baudry, C., Bertrand, O., Delpuech, C., and Pernier, J. Oscillatory $\gamma$-band $(30-70 \mathrm{~Hz})$ activity induced by a visual search. J. Neurosci. 17 : 722-734, 1997.

Tardif, E., Richer, L., Bergeron, A., Lepore, F., and Guillemot, J.-P. Spatial resolution and contrast sensitivity of single neurons in area 19 of split-chiasm cats: a comparison with primary visual cortex. Eur. J. Neurosci. 9: $1929-1939,1997$

Tettoni, L., Gheorghita-Baechler, F., Bressoud, R., Welker, E., and INNOCENTI, G. M. Constant and variable aspects of axonal phenotype in cerebral cortex. Cereb. Cortex 8: 543-552, 1998.

Titinen, H., SinkKonen, J., Reinikainen, K., Alho, K., Lavikainen, J., And NÄÄTÄNEN, R. Selective attention enhances the auditory $40-\mathrm{Hz}$ response in humans. Nature 364: 59-60, 1993.

Tootell, R.B.H., Mendola, J. D., Hadikhani, N. K., Ledden, P. J., Liu, A. K., Reppas, J. B., Sereno, M. I., And Dale, A. M. Functional analysis of V3A and related areas in human visual cortex. J. Neurosci. 17: 7060-7078, 1997.

Tootell, R.B.H., Reppas, J. B., Kwong, K. K., Malach, R., Born, R. T., Brady, T. J., Rosen, B. R., and Belliveau, J. W. Functional analysis of human MT and related visual cortical areas using magnetic resonance imaging. J. Neurosci. 15: 3215-3230, 1995.

TREVARTHEN, C. Integrative functions of the cerebral commissures. In: Handbook of Neuropsychology, edited by F. Boller and J. Grafman. Amsterdam: Elsevier, 1990, p. 49-83.

VAn Essen, D. C. AND DruRy, H. A. Structural and functional analyses of human cerebral cortex using a surface-based atlas. J. Neurosci. 17: 7079$7102,1997$.

Vanni, S., Revonsuo, A., and Hari, R. Modulation of the parieto-occipital alpha rhythm during object detection. J. Neurosci. 17: 7141-7147, 1997.

VON DER MALSBURG, C. Binding in models of perception and brain function. Curr. Opin. Neurobiol. 5: 520-526, 1995.

ZeKI, S. A Vision of the Brain. Oxford, UK: Blackwell Scientific Publication, 1993.

Zilles, K. AND Clarke, S. Architecture, connectivity, and transmitter receptors of human extrastriate visual cortex. In: Cerebral Cortex, edited by K. S. Rockland, J. H. Kaas, and A. Peters. New York: Plenum, 1997, vol. 12, p. 673-742. 